\title{
Prevalence of familial hypercholesterolemia: a meta-analysis of six large, observational, population-based studies in Poland
}

\author{
Andrzej Pajak ${ }^{1}$, Krystyna Szafraniec ${ }^{1}$, Maciej Polak ${ }^{1}$, Wojciech Drygas ${ }^{2,3}$, Walerian Piotrowski ${ }^{2}$, \\ Tomasz Zdrojewski ${ }^{4}$, Piotr Jankowski ${ }^{5}$
}

\begin{abstract}
1Department of Epidemiology and Population Studies, Institute of Public Health, Faculty of Health Sciences, Jagiellonian University Medical College, Krakow, Poland ${ }^{2}$ Department of Epidemiology, Cardiovascular Disease Prevention and Health Promotion, Institute of Cardiology, Warsaw, Poland

${ }^{3}$ Department of Preventive Medicine, Medical University of Lodz, Lodz, Poland ${ }^{4}$ Department of Prevention and Medical Education, Medical University of Gdansk, Gdansk, Poland

${ }^{5}$ Department of Intensive Electrotherapy and Hypertension, Jagiellonian University Medical College, Krakow, Poland
\end{abstract}

Submitted: 26 November 2015

Accepted: 27 February 2016

Arch Med Sci 2016; 12, 4: 687-696

DOI: 10.5114 /aoms.2016.59700

Copyright @ 2016 Termedia \& Banach

\section{Abstract}

Introduction: Familial hypercholesterolemia $(\mathrm{FH})$ is a severely underdiagnosed and undertreated genetic disorder. Little is known about regional variation in the prevalence of $\mathrm{FH}$, and information for Central and Eastern Europe (CEE) is scarce. This paper assesses the prevalence of $\mathrm{FH}$ and related cardiovascular disease (CVD) risk factors in Poland.

Material and methods: We performed a meta-analysis of six population-based studies in Poland. The FH was assessed using the Dutch Lipids Clinics Network (DLCN) criteria. The categories "definite" (> 8 points) and "probable" (6-8 points) were combined into "potential FH". Combined estimates of proportions across studies were pooled by meta-analysis with a random effects model.

Results: A total of 37,889 persons aged 20-79 years were included in the analysis. The distribution of DLCN scores was skewed, and there were only 7 cases of definite FH. Prevalence of potential FH was 404/100,000 people (95\% Cl = 277-531/100,000). Familial hypercholesterolemia was more prevalent in women than in men, and the prevalence was the highest in the age group 45-54 years in men and 55-64 years in women. After adjustment for age and sex, compared to participants with normal cholesterol, persons with potential $\mathrm{FH}$ had twice the prevalence of hypertension $(p<0.01)$; smoking was more prevalent by about $80 \%(p<0.01)$ and hypertriglyceridemia was nine times more frequent $(p<0.001)$. There was no difference in the prevalence of low high-density lipoprotein (HDL)-cholesterol or diabetes.

Conclusions: We believe that our study might facilitate the planning of a strategy to manage the disease at a population level, i.e. to develop a national strategy for the detection, diagnosis, and treatment of FH.

Key words: familial hypercholesterolemia, Dutch Lipids Clinics Network criteria, risk factors, epidemiology, prevalence.
Corresponding author: Prof. Andrzej Pajak MD, PhD Department of Epidemiology and Population Studies Institute of Public Health Faculty of Health Sciences Jagiellonian University Medical College 20 Grzegórzecka St 31-531 Krakow, Poland Phone: +48 124332841 E-mail: andrzej.pajak@ uj.edu.pl 


\section{Introduction}

Familial hypercholesterolemia (FH) is an autosomal dominant condition characterized by the life-course elevated blood low-density lipoprotein (LDL)-cholesterol concentration. In most cases, mutations of the gene for the $L D L$ receptor (LDLR) or for apoprotein $B(A p o B)$ or for proprotein convertase subtilisin/kexin type 9 (PCSK9) are found, but other forms of genetic mutations can also exist as very rare mutations of the LDLR adaptor protein 1 pathway. A vast majority of people with $\mathrm{FH}$ are heterozygotes. Heterozygous mutations of LDLR are present in about $90 \%$ of $\mathrm{FH}$ cases, while $A$ poB and PCSK9 were found in $5 \%$ and $1 \%$, respectively [1-3]. Familial hypercholesterolemia has been well recognized for over 50 years, but it has gained attention recently for several important reasons. First, it is related to early atherosclerosis and premature coronary heart disease (CHD) and people with heterozygous $\mathrm{FH}$ are automatically considered as high-risk patients [4, 5]. Second, in many countries, the condition remains severely underdiagnosed and undertreated. Out of 22 countries, in more than half the estimates of the proportion of individuals diagnosed with $\mathrm{FH}$ were not higher than $1 \%$ of all cases, and only in five countries did the proportion exceed $5 \%$, reaching the absolutely exceptional maximum of $71 \%$ in the Netherlands [3]. Only about half of FH patients were receiving appropriate therapy $[4,6]$. Furthermore, $\mathrm{FH}$ patients were more likely to smoke and to have a high concentration of blood triglycerides and lower chance of having blood pressure within the recommended limits [6]. Statins are considered to be the first-line therapy for patients with FH [7-9], but low-potency statins or moderate doses of higher potency statins are not effective enough. In consequence, higher doses of high-potency statins are often needed to reach the goal of lowering LDL-C levels by $50 \%$ at least. Combined treatment with ezetimibe, ER niacin, bile acid binding agents, or anti-PCSK9 antibodies is also postulated [10-12]. The problem of statin intolerance is of particular importance as it affects $10-15 \%$ of patients treated with statins in general, with some complications having been reported more with the use of synthetic, potent, and more lipophilic statins [13].

All this suggests that $\mathrm{FH}$ requires a specific detection and treatment strategy that is firmly based on epidemiological evidence. It used to be generally believed that homozygous FH occurs in about $1 / 100,000$ people, and heterozygous $\mathrm{FH}$ in about $1 / 500$. However, these numbers were questioned because they were derived mainly from old clinical data. More recent studies indicated that the prevalence may reach $1 / 200$ [3]. Data on prevalence of FH are not available for most countries because there is a lack of national registers or screening strategies in action. Furthermore, uniform criteria for the diagnosis of $\mathrm{FH}$ are not agreed, and there are three sets of criteria at least in broader use depending on the region of the world [2]. Genetic testing would be particularly beneficial to confirm the diagnosis in every individual case, but genetic screening was not found to be a cost-effective tool [14, 15].

The spectrum of $\mathrm{FH}$ mutations in Europe varies by country [2]. It is likely that there is also regional variation in the prevalence of $\mathrm{FH}$ in general. Information for Eastern Europe is scarce. Even the flagship report on $\mathrm{FH}$ of the European Atherosclerosis Society does not provide an estimate for diagnosed $\mathrm{FH}$ for a single Central or East European (CEE) country [3]. The findings in patients after hospitalization due to CHD indicate that the prevalence of $\mathrm{FH}$ seems to be high in CEE countries including Poland, in which $11.4 \%$ of patients were found to have definite or probable FH [6]. In Poland, several large population-based studies have been conducted, but the problem of $\mathrm{FH}$ was not addressed in any of them, as each of these studies had too low statistical power to deliver a more precise estimate.

The goal of this study was to assess the prevalence of $\mathrm{FH}$ and related cardiovascular disease (CVD) risk factors by a meta-analysis of the results of six large, population-based, observational studies carried out in Poland, using available data on phenotype of $\mathrm{FH}$.

\section{Material and methods}

We used data from six population studies, carried out in Poland in well-defined populations, in which at least 2,000 participants were examined. Detailed descriptions of the methods used in particular studies have been published elsewhere [16-23]. The list of populations studied and the information on recruitment and participation are presented in Table I.

For the present analysis, FH was assessed using the Dutch Lipids Clinics Network (DLCN) criteria for diagnosis of heterozygous $\mathrm{FH}$ in adults $[3,24]$. Participants were classified as follows: "definite $\mathrm{FH}$ " if they scored $>8$ points, "probable $\mathrm{FH}$ " if they scored 6-8 points, and "possible $\mathrm{FH}$ " if they scored 3-5 points. In addition, categories "definite $\mathrm{FH}$ " and "probable $\mathrm{FH}$ " were combined into "potential FH." The category "normal blood cholesterol" was defined as having total cholesterol $(\mathrm{TC})<5 \mathrm{mmol} / \mathrm{l}$ and LDL-C $<3 \mathrm{mmol} / \mathrm{l}$ and not being on blood lipid-lowering treatment. In all studies, data on tendon xanthomas and arcus cornealis in participants or their families as well as data on first-degree relatives and children with LDL-C $>95^{\text {th }}$ percentile by age and gender were not available. Also, no molecular genetic testing 


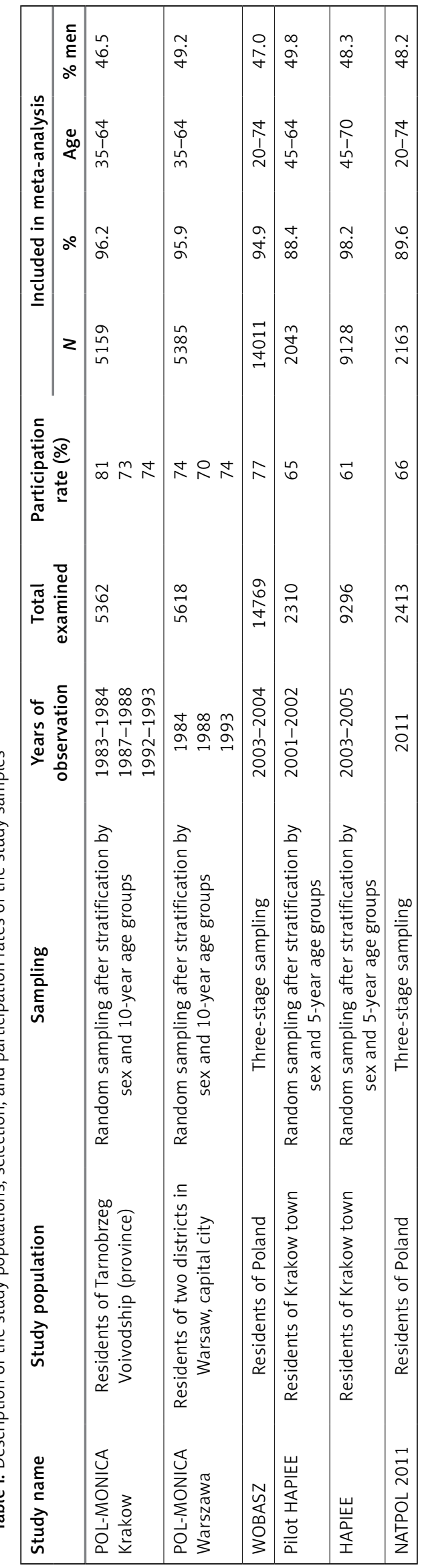

\begin{tabular}{|c|c|c|c|c|c|c|}
\hline لُدّ & 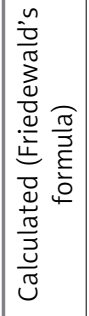 & 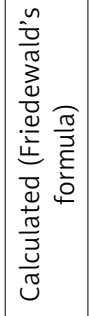 & 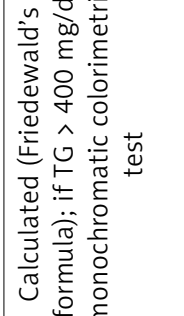 & 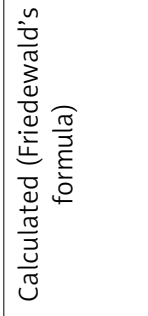 & 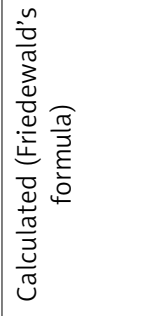 & 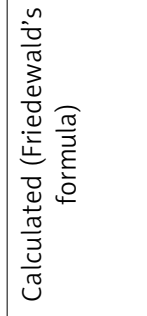 \\
\hline$\stackrel{\circ}{-}$ & 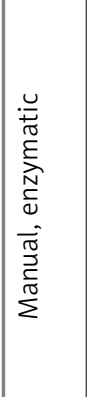 & 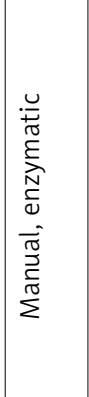 & 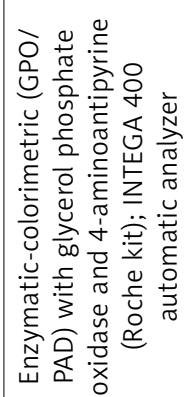 & 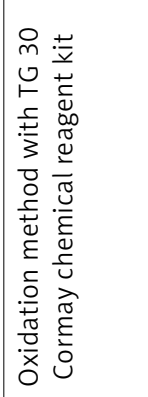 & 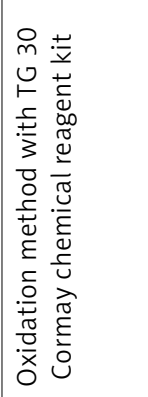 & 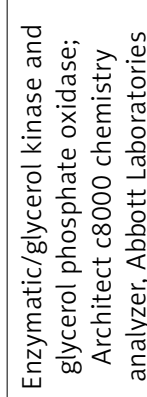 \\
\hline 롬 & 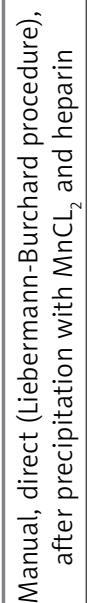 & 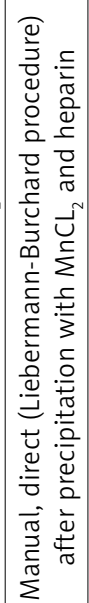 & 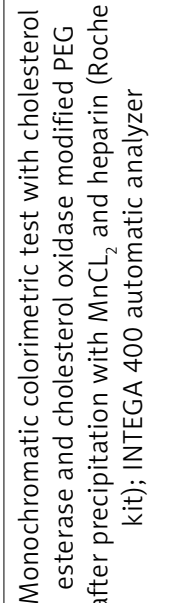 & 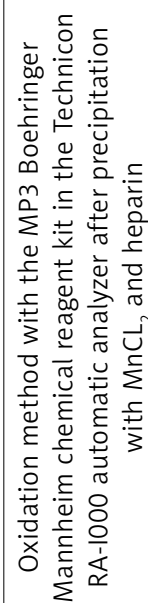 & 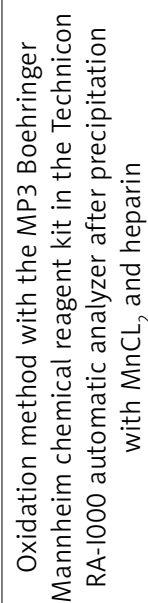 & 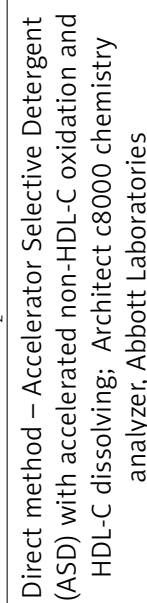 \\
\hline$\stackrel{\sim}{\llcorner}$ & 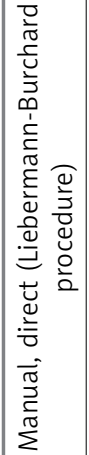 & 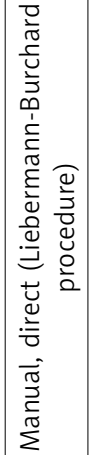 & 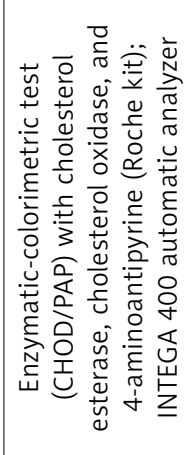 & 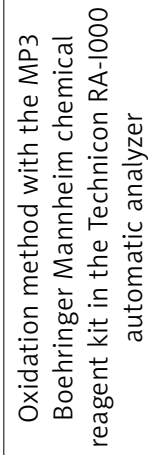 & 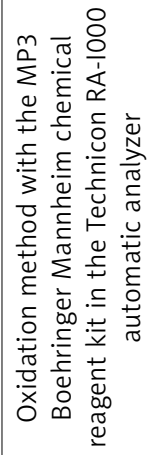 & 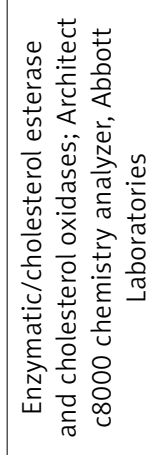 \\
\hline $\begin{array}{l}\frac{\bar{\sigma}}{2} \\
\frac{\bar{d}}{2} \\
\sum\end{array}$ & 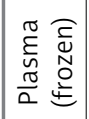 & 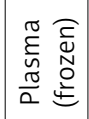 & 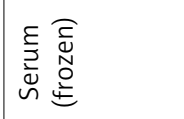 & $\begin{array}{l}\frac{\tilde{\sigma}}{\bar{N}} \\
\frac{\pi}{\alpha}\end{array}$ & \begin{tabular}{|l}
$\frac{\pi}{5}$ \\
$\frac{\pi}{\pi}$ \\
$\frac{\pi}{\alpha}$
\end{tabular} & 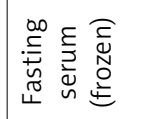 \\
\hline 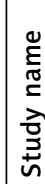 & 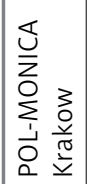 & 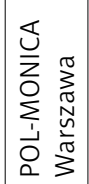 & $\begin{array}{l}\text { N } \\
\hat{x} \\
0 \\
0 \\
3\end{array}$ & 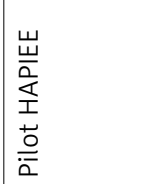 & 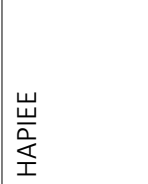 & 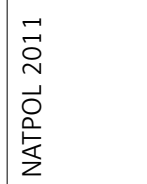 \\
\hline
\end{tabular}




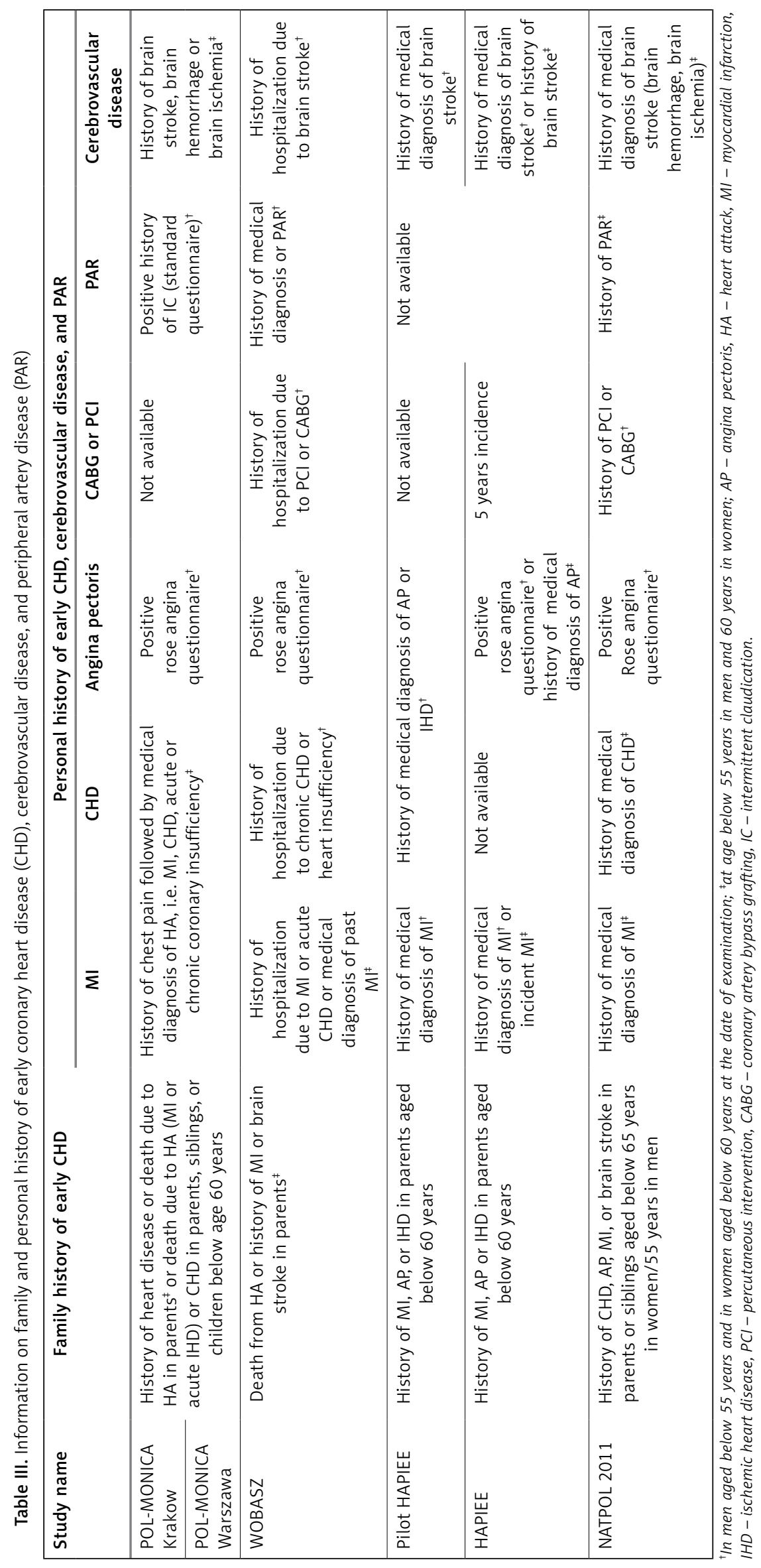


was available, so the final classification was based on phenotype characteristics, i.e. blood LDL-cholesterol and family or personal history of CHD and other acute atherosclerosis manifestations. The methods of blood processing and lipid determination are presented in Table II. In all studies, the information on family and personal history was collected by interview according to the questionnaire. All the available and relevant information on personal and family history of early CHD, stroke, and peripheral arterial disease (PAR) was used. Table III presents the information obtained to be used in the DLCN classification of FH.

\section{Statistical analysis}

In the first stage, calculations in each of the studies were conducted separately. Proportions in persons with $\mathrm{FH}$ and in persons with normal blood cholesterol were standardized directly to the sex-specific age distribution of the Polish population at the end of 2013. Then, combined estimates of proportions across studies were pooled by meta-analysis technique. In the presence of heterogeneity within and between studies, random effects methodology was chosen to obtain pooled prevalence [25]. The prevalence of $\mathrm{FH}$ by sex and age strata was obtained by much the same procedure except for the two extreme age groups (20-34 years, 65 years and over), in which fixed effect meta-analysis was applied. A similar two-step approach was performed to determine the association between $\mathrm{FH}$ and CVD risk factors. First, a set of multiple regressions was carried out with risk factors as dependent variables and the $\mathrm{FH}$ vs. healthy group as the independent variable, adjusted for age and sex. The second step was to implement random effects model meta-analysis to calculate the combined measure of association across the studies. The statistical calculations were performed with IBM SPSS Statistics 22 for Windows except the meta-analysis procedure. The R Metafor package [26] was used to pool estimates across the studies $p<0.05$ was considered statistically significant.

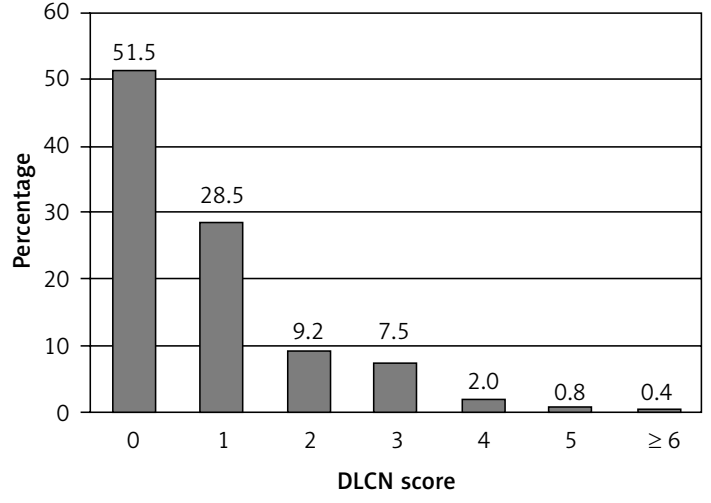

Figure 1. Distribution of Dutch Lipid Consensus Network (DLCN) score

\section{Results}

Out of 39,768 participants examined in six studies, 37,889 individuals (47.8\% men) were included in the present meta-analysis. About 1,885 (4.7\%) participants were excluded, mainly because of missing LDL-C (1,343 persons) or the age being outside the range specific for each study at the date of examination (542 persons). The detailed recruitment and participation numbers by study are given in Table I.

Severe hypercholesterolemia was not frequently found in the pooled sample included in the analysis. Very high LDL-cholesterol $(\geq 6.5 \mathrm{mmol} / \mathrm{l})$ was found only in $4.34 \%$ o (95\% Cl: $3.19-5.48 \%$ ) and $\mathrm{LDL}-\mathrm{C} \geq 5 \mathrm{mmol} / \mathrm{l}$ was found in $5.79 \%(95 \% \mathrm{Cl}$ : $4.52-7.05 \%)$ of all participants. The distribution of the DLCN scores was skewed, and about half of all participants had a DLCN score of zero (Figure 1). In all 37,889 individuals studied, there were only 7 cases of DLCN score $>8$ points. Potential FH, i.e. definite and probable FH combined (score $\geq 6$ points), was more prevalent. The average prevalence was 404/100,000 people (95\% Cl: 277-531/100,000). However, the estimate of the average prevalence varied by study, with the minimum of $231 / 100,000$ and maximum of 548/100,000 (Table IV).

In Table V, the prevalence of potential and possible $\mathrm{FH}$ is presented by sex and by age group. Fa-

Table IV. Prevalence of potential (definite and probable combined) and possible familial hypercholesterolemia (FH) according to the Dutch Lipids Clinics Network (DLCN) criteria

\begin{tabular}{|c|c|c|c|c|}
\hline \multirow[t]{2}{*}{ Study name } & \multicolumn{2}{|c|}{ Potential FH } & \multicolumn{2}{|c|}{ Possible FH } \\
\hline & $\%$ & $95 \% \mathrm{Cl}$ & $\%$ & $95 \% \mathrm{Cl}$ \\
\hline POL-MONICA Krakow & 4.46 & $2.64-6.28$ & 12.1 & $11.2-13.0$ \\
\hline POL-MONICA Warszawa & 5.01 & $3.13-6.90$ & 13.5 & $12.6-14.5$ \\
\hline WOBASZ & 2.46 & $1.63-3.28$ & 8.1 & $7.6-8.5$ \\
\hline Pilot HAPIEE & 5.38 & $2.21-8.56$ & 12.9 & $11.4-14.3$ \\
\hline HAPIEE & 5.48 & $3.96-6.99$ & 12.2 & $11.5-12.9$ \\
\hline NATPOL 2011 & 2.31 & $0.29-4.34$ & 5.9 & $4.9-6.9$ \\
\hline Total & 4.04 & $2.77-5.31$ & 10.4 & $8.9-12.7$ \\
\hline
\end{tabular}




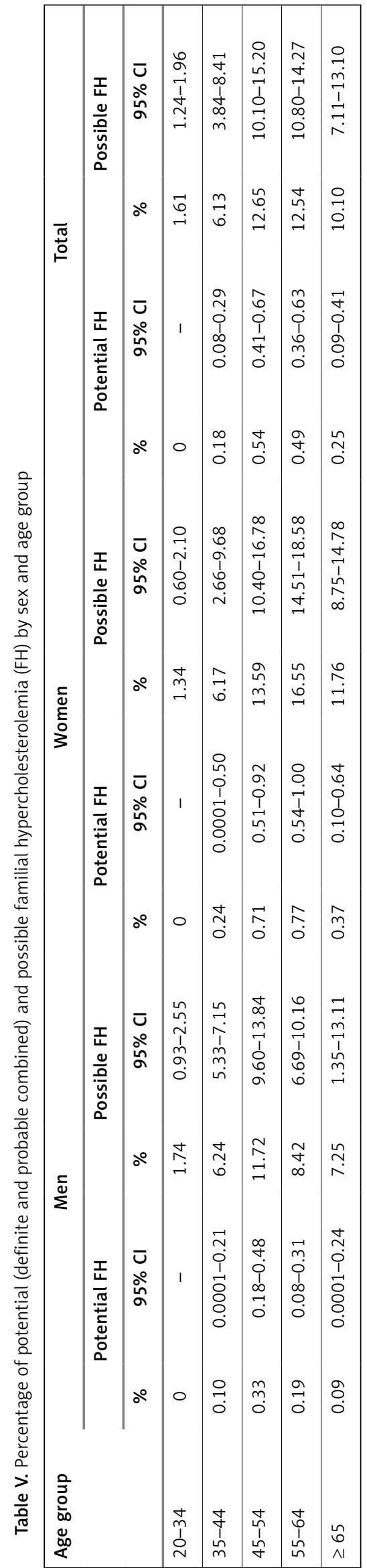

milial hypercholesterolemia was more prevalent in women than in men, and the prevalence was the highest in the age group 45-54 years in men and 55-64 years in women. At age 65 years and older in men, the prevalence of FH was almost three times lower than the peak, and at age 65 years and older in women it was twice as low as the peak.

In Table $\mathrm{VI}$, the characteristics of participants with potential and possible $\mathrm{FH}$ are compared with persons with normal blood cholesterol, i.e. $\mathrm{TC}<5 \mathrm{mmol} / \mathrm{l}$ and LDL-C $<3 \mathrm{mmol} / \mathrm{l}$. Persons with $\mathrm{FH}$ were older and included a higher proportion of women. By definition, positive history of CHD and other acute manifestations of atherosclerosis were more frequent in participants with $\mathrm{FH}$. Still, about $10 \%$ of participants with normal blood cholesterol had a history of stroke or acute or chronic CHD.

Participants with potential and with possible $\mathrm{FH}$ had higher exposure to some other risk factors. After adjustment for age and sex, compared to participants with normal cholesterol, persons with potential $\mathrm{FH}$ had twice as high prevalence of hypertension; smoking was more prevalent by about $80 \%$ and hypertriglyceridemia nine times more frequent. The prevalence of these risk factors was also higher in participants with possible $\mathrm{FH}$; in particular, the prevalence of hypertriglyceridemia was four times higher compared to participants with normal blood cholesterol. Also, in participants with possible $\mathrm{FH}$, higher prevalence of obesity was found. The prevalence of low HDL-cholesterol and diabetes was similar in participants with $\mathrm{FH}$ and in participants with normal blood cholesterol (Table VII).

\section{Discussion}

We found that the prevalence of $\mathrm{FH}$ in Poland was between 277 and 531/100,000 people. The average estimate was 404/100,000, which equates to approximately $1 / 250$ people.

To our best knowledge, this is the first estimate of the prevalence of $\mathrm{FH}$ in Poland, which is based on the results of larger studies carried out in well-defined populations. Furthermore, the studies included in the present meta-analysis used the standardized methods of observations, and in some cases, the methods were standardized across these studies to obtain comparable results. For example, the POL-MONICA Krakow and Warsaw studies used the same questionnaires and blood collection procedures, and laboratory procedures were subjected to the same external quality control programs carried out by the CDC in Atlanta (USA) and by the MONICA Project Lipid Reference Center [16-18]. The WOBASZ Study used questionnaires largely based on POL-MONICA experiences, and biochemical analyses were carried out in the same laboratory as in POL-MONICA 
Table VI. Descriptive statistics for participants with potential (definite and probable combined) and possible familial hypercholesterolemia (FH) according to the Dutch Lipids Clinics Network (DLCN) criteria and for participants with normal blood cholesterol (TC $<5 \mathrm{mmol} / \mathrm{l}$ and $\mathrm{LDL}-\mathrm{C}<3 \mathrm{mmol} / \mathrm{l}$ )

\begin{tabular}{|c|c|c|c|c|c|c|}
\hline \multirow[t]{2}{*}{ Parameter } & \multicolumn{2}{|c|}{ Potential FH } & \multicolumn{2}{|c|}{ Possible FH } & \multicolumn{2}{|c|}{ Normal blood lipids } \\
\hline & $\begin{array}{c}\text { Mean } \\
\text { or \% }\end{array}$ & $95 \% \mathrm{Cl}$ & $\begin{array}{c}\text { Mean } \\
\text { or } \%\end{array}$ & $95 \% \mathrm{Cl}$ & $\begin{array}{c}\text { Mean } \\
\text { or } \%\end{array}$ & $95 \% \mathrm{Cl}$ \\
\hline Mean age [years] & 53.8 & $52.8-54.8$ & 53.4 & $51.7-55.1$ & 46.2 & $39.7-52.7$ \\
\hline Men (\%) & 27.3 & $20.3-34.4$ & 39.6 & $36.3-43.0$ & 49.3 & $46.1-52.5$ \\
\hline Mean BMI [kg/m²] & 27.8 & $27.0-28.5$ & 28.1 & $28.0-28.3$ & 26.1 & $25.2-27.1$ \\
\hline Current smokers (\%) & 41.3 & $33.5-49.1$ & 34.5 & $28.2-40.9$ & 36.0 & $31.1-40.9$ \\
\hline Diabetes (\%) & 1.8 & $<0.1-3.9$ & 8.1 & $4.7-11.6$ & 5.6 & $1.7-9.5$ \\
\hline Hypertension (\%) & 68.6 & $60.9-76.3$ & 62.9 & $61.3-64.4$ & 41.1 & $30.4-51.9$ \\
\hline History of CVD (\%) & 70.1 & $56.9-83.2$ & 48.9 & $39.3-58.5$ & 12.1 & $7.4-16.8$ \\
\hline History of MI (\%) & 32.1 & $15.0-49.2$ & 16.7 & $9.9-23.4$ & 3.2 & $1.7-4.7$ \\
\hline History of CABG or PCI (\%) & 6.5 & $<0.1-15.4$ & 3.2 & $1.8-4.7$ & 0.6 & $0.1-1.0$ \\
\hline History of AP (\%) & 49.3 & $29.3-69.3$ & 35.0 & $23.6-46.4$ & 8.6 & $4.6-12.5$ \\
\hline History of brain stroke (\%) & 3.2 & $<0.1-6.6$ & 2.9 & $2.3-3.4$ & 1.3 & $0.9-1.7$ \\
\hline History of PAR (\%) & 2.5 & $<0.1-5.8$ & 4.5 & $2.3-6.7$ & 1.2 & $0.7-1.6$ \\
\hline CVD and diabetes (\%) & 1.8 & $<0.1-4.0$ & 4.9 & $2.8-7.0$ & 1.5 & $0.5-2.5$ \\
\hline Lipid-lowering treatment (\%) & 14.1 & $3.6-24.6$ & 16.9 & $8.6-25.2$ & - & - \\
\hline Mean TC $[\mathrm{mmol} / \mathrm{l}]$ & 8.7 & $8.2-9.2$ & 6.8 & $6.6-7.0$ & 4.3 & $4.3-4.4$ \\
\hline Mean HDL-C [mmol/l] & 1.4 & $1.4-1.5$ & 1.4 & $1.4-1.4$ & 1.4 & $1.4-1.49$ \\
\hline Mean LDL-C [mmol/l] & 6.4 & $6.0-6.9$ & 4.6 & $4.4-4.8$ & 2.4 & $2.3-2.4$ \\
\hline TG (median, min-max) [mmol/l] & 1.9 & $0.4-4.4$ & 1.6 & $0.3-4.7$ & 1.0 & $0.2-4.5$ \\
\hline
\end{tabular}

$B M I$ - body mass index, CVD - cardiovascular disease, AP - angina pectoris, HA - heart attack, MI - myocardial infarction, $P C l$ - percutaneous intervention, $C A B G$ - coronary artery bypass grafting, PAR-peripheral artery disease, TC-total cholesterol, $H D L-C-$ highdensity lipoprotein cholesterol, $L D L$ - low-density lipoprotein cholesterol, TG - triglycerides.

Table VII. Relation between familial hypercholesterolemia (FH) and prevalence of other cardiovascular disease (CVD) risk factors (reference group = participants with $\mathrm{TC}<5 \mathrm{mmol} / \mathrm{l}$ and $\mathrm{LDL}<3 \mathrm{mmol} / \mathrm{l}$ and not on blood lipid lowering treatment)

\begin{tabular}{|c|c|c|c|c|c|c|}
\hline \multirow[t]{2}{*}{ Parameter } & \multicolumn{3}{|c|}{ Potential FH } & \multicolumn{3}{|c|}{ Possible FH } \\
\hline & $\mathrm{OR}^{*}$ & $95 \% \mathrm{Cl}$ & $P$-value & $\mathrm{OR}^{\star}$ & $95 \% \mathrm{Cl}$ & $P$-value \\
\hline $\mathrm{BMI} \geq 30 \mathrm{~kg} / \mathrm{m}^{2}$ & 1.16 & $0.80-1.68$ & 0.44 & 1.25 & $1.10-1.41$ & 0.0006 \\
\hline Smoking & 1.75 & $1.23-2.48$ & 0.002 & 1.27 & $1.16-1.39$ & $<0.0001$ \\
\hline Diabetes & 2.26 & $0.85-6.00$ & 0.10 & 1.17 & $0.91-1.50$ & 0.21 \\
\hline Hypertension & 2.02 & $1.95-3.43$ & 0.009 & 1.76 & $1.57-1.97$ & $<0.0001$ \\
\hline Low HDL-C & 1.66 & $0.84-3.27$ & 0.14 & 1.31 & $1.08-1.60$ & 0.006 \\
\hline $\mathrm{TG}>1.7 \mathrm{mmol} / \mathrm{l}$ & 9.05 & $6.10-13.44$ & $<0.0001$ & 4.37 & $3.71-5.14$ & $<0.0001$ \\
\hline
\end{tabular}

$B M I$ - body mass index, TC - total cholesterol, HDL-C - high-density lipoprotein cholesterol, LDL - low-density lipoprotein cholesterol, $T G$ - triglycerides, *Adjusted for age and sex.

Warsaw. The methods in HAPIEE Krakow and the Pilot HAPIEE study were the same, and biochemical analyses were done in a laboratory that participated in the POL-MONICA Krakow study. Also, the strength of the analysis is that we were able to include data from two studies in which samples studied were selected from the total Polish population (WOBASZ and NATPOL 2011). 
There are, however, certain limitations in the interpretation of the results. The first is that none of the studies included in the meta-analysis was designed to assess FH according to the DLCN or any other standard set of diagnostic criteria. The information on phenotype and family history in particular varied between the studies. This could bias the final results, resulting in decreased numbers of people classified with definite or probable $\mathrm{FH}$. The samples studied differed in age. Including the age group below 35 years could result in a decrease in the number of detected cases, as in heterozygous $\mathrm{FH}$ the onset of CHD frequently appears after the age of 35 years. On the other hand, in the older age group, the proportion of persons with $\mathrm{FH}$ was smaller because of lower life expectancy and higher frequency of the use of blood lipid-lowering agents. Indeed, in studies which involved samples with a broader age span (WOBASZ and NATPOL 2011), the rates of FH were lower. In participants aged 60-79 years (NATPOL 2011 study), the proportion of people taking statins was three times higher than the average for the total sample [22]. Blood lipid-lowering treatment could also lower the rates of $\mathrm{FH}$ in general. This would not be a problem of the early studies as treatment for hypercholesterolemia was infrequent, even marginal. The advantage of using data from the older studies might be that the bias due to the lipid-lowering treatment would be smaller than in more current observations. Indeed, in the later studies, the proportions of treated people were higher than in the old studies, but treatment of hypercholesterolemia was still not a standard practice. In the WOBASZ study (a representative sample for Poland), only $12 \%$ of people with hypercholesterolemia received treatment, and out of them, the treatment goals were reached only in every fifth person [19]. In the most recent study (NATPOL 2011), the proportion was similar [22]. It is likely that the effect of blood lipid-lowering treatment on our results was rather small. In the Finnish population study, mutation carriers who were treated with lipid-lowering medication had similar LDL-C to carriers who were not treated [27]. Also, lack of information on genetic mutations might be of smaller importance, as in the untreated, predominantly middle-age population, cases of $\mathrm{FH}$ with normal blood LDL-C or only slightly over the normal values should be very rare.

Like in the other studies, there were differences in $\mathrm{FH}$ prevalence according to age $[4,6,28$, 29], which could be explained by the impact of increasing age and weight on LDL-C when using DLCN criteria. Higher prevalence in women was also found in some studies $[4,6,30]$ but not in all [28-30]. Besides the effects of age and weight, these observations can also be explained by the differences in life expectancy between men and women. Familial hypercholesterolemia was found to be related to higher exposure to other CVD risk factors. Our study design does not allow for conclusions on causality, but these results call for intensifying the intervention in clinical practice.

Direct comparisons between our findings and the results of other studies are difficult due to the differences in the design and methods used. Most evidence on the prevalence of $\mathrm{FH}$ is based on data from registers whose coverage is difficult to control [31]. In a few studies, the studied samples were representative of a larger population, but they were rarely large enough to provide reliable estimates of the prevalence. Our estimate is slightly lower compared to the results of the well-designed and frequently cited Danish study and close to the estimate of the European Atherosclerosis Society $[3,4]$. Also, our results are close to the results obtained using similar methods from the US NHANES 2001-2012 datasets (nearly 60,000 persons) and similar to results of the studies from Australia and China (18,000 and 10,000 persons respectively) [28-30]. Our estimate of the prevalence is twice as high compared to the Finnish study (over 28,000 persons), which was based on finding genetic mutations which are present in about $70 \%$ of all FH cases in Finland [27].

Observations from the younger groups of the Polish population, i.e. below the age of 20 years, would add complementary information leading to better assessment of $\mathrm{FH}$ in the Polish population. However, it is unlikely that it will be accomplished in the near future, as cholesterol screening is not recommended for people below the age of 18 years. The postulated tool for the detection of $\mathrm{FH}$ is cascade screening. This is based on detailed examinations of the first- and second-degree relatives of the probands (index cases). The latter might emerge from either by-chance examination or from the population screening, which would provide information on blood cholesterol, premature CHD, and cardiac deaths in family members or tendon xanthomas in the proband or his/her family member $[3,5,8,32]$.

We believe that our study allows for a better understanding of how many cases of $\mathrm{FH}$ can emerge from the population cholesterol screening facilitating the planning of a strategy to manage the disease at a population level. We hope that our results will draw the attention of health managers and clinicians, particularly primary care physicians involved in population cholesterol screening in the group of people with potential $\mathrm{FH}$. In Poland, a country with 38 million residents, the size of this group is about $150,000 \pm 50,000$ adult people. These people require special diagnostics which would involve not only themselves but also all of their first- and second-degree relatives and which would include genetic testing and other 
more sophisticated biochemical diagnostics. Furthermore, it could be expected that many of them would require intensive treatment with high doses of highly potent statins alone or in combination with other lipid-lowering agents including new generations of efficacious drugs [24, 33]. All these points need to be addressed urgently, to develop a national strategy for the detection, diagnosis, and treatment of $\mathrm{FH}$.

\section{Acknowledgments}

The authors express their gratitude to all participants and investigators of the POL-MONICA, HAPIEE, WOBASZ, and NATPOL studies.

POLMONICA and the HAPIEE pilot study were supported by the Polish Committee of Scientific Research [4 1474 9101, 1992-93, 4 P05D 036 08, 253//S4/92/02, 380/p05/95/08 and 4 PO5D 019 18]; WOBASZ by the Polish Ministry of Health [program POLKAD 2003-2005, 4.12.1]; HAPIEE by the Wellcome Trust [WT081081] and by the US National Institute of Aging [Grant Number R01 AG23522]; NATPOL 2011 was supported by unrestricted grants from Sanofi-Aventis, Abbott Laboratories Poland Ltd, Siemens Ltd and Polpharma. This work was supported in part by Amgen. Funding bodies and sponsors had no role in the design, data collection, data analysis, data interpretation, or writing of this report.

\section{Conflict of interest}

AP was paid an honorarium for consultancy from Amgen. PJ has received honoraria or grants from Amgen, KRKA, Polpharma, MSD, and Sanofi.

\section{References}

1. Austin M, Hutter C, Zimmerman R, et al. Genetic causes of monogenic heterozygous familiar hypercholesterolemia at HuGE prevalence review. Am J Epidemiol 2004; 160: 407-420.

2. Nair DR, Sharifi M, Al-Rasadi K. Familiar hypercholesterolemia. Curr Opin Cardiol 2014; 29: 381-8.

3. Nordestgaard B, Chapman M, Humphries S, et al. Familiar hypercholesterolemia is underdiagnosed and untreated in general population; guidance for clinicians to prevent coronary heart disease. Eur Heart J 2013; 34: 3478-90.

4. Benn M, Watts G, Tybjaerg-Hansen A, Nordestgaard B, Nordestgaard B. Familiar hypercholesterolemia in the Danish general population: prevalence, coronary artery disease and cholesterol-lowering medication. J Clin Endocrinol Metab 2012; 97: 3956-64.

5. The Fifth Joint Task Force of the European Society of Cardiology and Other Societies on Cardiovascular Disease Prevention in Clinical Practice. European Guidelines on cardiovascular disease prevention in clinical practice (version 2012). Eur Heart J 2012; 33: 1635-701.

6. De Backer G, Besseling J, Chapman J, et al. Prevalence and management of familiar hypercholesterolemia in coronary patients: an analysis of EUROASPIRE IV, a study of the European Society of Cardiology. Atherosclerosis 2015; 241: 169-175.

7. Goldberg A, Hopkins P, Toth P, et al. Familial hypercholesterolemia: screening, diagnosis and management of pediatric and adult patients: clinical guidance from the National Lipid Association Expert Panel on Familial Hypercholesterolemia. J Clin Lipidol 2011; 5: S1-8.

8. Third Report of the National Cholesterol Education Program (NCEP) Expert Panel on Detection, Evaluation, and Treatment of High Blood Cholesterol in Adults (Adult Treatment Panel III). Circulation 2002; 106: 3143-421.

9. Minhas R, Humphries S, Qureshi N, Neil H. Controversies in familial hypercholesterolaemia: recommendations of the NICE Guideline Development Group for the identification and management of familial hypercholesterolaemia. Heart 2009; 95: 584-7.

10. Robinson J. Management of familial hypercholesterolemia. J Manag Care Pharm 2013; 19: 139-49.

11. Robinson J, Nedergaard B, Rogers W, et al. Effect of evolocumab or ezetimbide added to moderate of high-intensity statin therapy on LDL-C lowering in ptients with hypercholesterolemia. JAMA 2014; 311: 1870-82.

12. Stroes E, Colquhoun D, Sullivan D, et al. Anti-PCSK9 antibody effectively lowers cholesterol in patients with statin intolerance: the GAUSS-2 randomized, placebo-controlled phase 3 clinical trial of evolocumab. JACC 2014; 63: 2541-8.

13. Banach M, Rizzo M, Tot, P, et al. Statin intolerance - an attempt at a unified definition. Position paper from an International Lipid Expert Panel. Arch Med Sci 2015; 11 : $1-23$.

14. Marks D, Wonderling D, Thorogood M, Lambert H, Humphries S, Neil A. Cost effectiveness analysis of different approaches of screening for familial hypercholesterolaemia. BMJ 2002; 324: 1303-6.

15. Chen C, Hay J. Cost-effectiveness analysis of alternative screening and treatment strategies for heterozygous familial hypercholesterolemia in the United States. Int J Cardiol 2015; 181: 417-24.

16. Rywik S, Pająk A. Monitoring of cardiovascular incidence, fatality and mortality trends and their determinants - longitudinal study Pol MONICA. Part III: principles of standardization and quality control. Przegl Lek 1985; 42: 280-4.

17. Rywik S, Sznajd J, Kulesza, W, et al. Monitoring of cardiovascular incidence, fatality and mortality trends and their determinants - longitudinal study Pol MONICA. Part II: material and methods. Przegl Lek 1985; 42: 256-60.

18. Döring A, Pająk A, Ferrario M, Grafnette RD, Kuulasmaa K. Methods of total cholesterol measurements in the baseline survey of the MONICA Project. Rev Epidem Sante Publ 1990; 38, 455-61.

19. Pająk A, Wiercińska E, Polakowska M, Kozakiewicz KE. Rozpowszechnienie dyslipidemii u mężczyzn i kobiet w wieku 20-74 lat w Polsce. Wyniki programu WOBASZ. Kardiol Pol 2005; 63 (Suppl. 4): S1-6.

20. Peasey A, Bobak M, Kubinova R, et al. Determinants of cardiovascular disease and other non-communicable diseases in Central and Eastern Europe: rationale and design of the HAPIEE study. BMC Public Health 2006; 6: 255-60.

21. Pająk A. Psychosocial and nutritional cardiovascular disease risk factors - longitudinal study. Assumptions, goals and methods of the screening survey. Przegl Lek 2002; 59: 993-8.

22. Zdrojewski T, Rutkowski M, Bandosz P, et al. Prevalence and control of cardiovascular risk factors in Poland. As- 
sumptions and objectives of the NATPOL 2011 Survey. Kardiola Pol 2013; 71: 381-92.

23. Rywik S, Kupść W, Piotrowski W, et al. Wieloośrodkowe ogólnopolskie badanie stanu zdrowia ludności - projekt WOBASZ. Założenia metodyczne oraz logistyka. Kardiol Pol 2005; 63 (Suppl. 4): S2-9.

24. Rynkiewicz A, Cybulska B, Banach M, et al. Management of familial heterozygous hypercholesterolemia: position paper of the Polish Lipid Expert Forum. J Clin Lipidol 2013; 7: 217-21.

25. Cochran W. The combination of estimates from different experiments. Biometrics 1954; 10: 101-29.

26. Viechtbauer W. Conducting meta-analyses in $\mathrm{R}$ with the Metafor package. J Statist Software 2010; 36: 1-48.

27. Lahtinen AM, Havulinna AS, Jula A, et al. Prevalence and clinical correlates of familial hypercholesterolemia founder mutations in the general population. Atherosclerosis 2015; 23: 64-9.

28. De Ferranti SD, Rodday MA, Mendelson M, et al. What is the prevalence of familial hypercholesterolemia in the US? American Heart Association 2014. Circulation 2014; 130 (Suppl II): A19656.

29. Shi Z, Youan B, Zhao D, et al. Familial hypercholesterolemia in China: prevalence and evidence of underdetection and undertreatment in a community population. Int J Cardiol 2014; 174: 834-6.

30. Watts GF, Shaw JE, Pang J, et al. Prevalence and treatment of familial hypercholesterolemia in Australian communities. Int J Cardiol 2015; 185: 69-71.

31. Vallejo-Vaz AJ, Seshasai SRK, Cole D, et al. Familial hypercholesterolemia: a global call to arms. Atherosclerosis 2015; 243: 257-9.

32. ESC/EAS Guidelines for the management of dyslipidaemias. Eur Heart J 2011; 32: 1769-818.

33. Myśliwiec $M$, Walczak M, Małecka-Tendera E, et al Management of familial hypercholesterolemia in children and adolescents. Position paper of the Polish Lipid Expert Forum. J Clin Lipidol 2014; 8: 173-80. 